\title{
SSR Molecular Marker and Analysis Report of Variety of Chicken for their Varying Weight
}

\author{
Ahmed Kareem Alatafi ${ }^{1}$, Kondapalli Kasturi ${ }^{2}$ \\ Acharya Nagarjuna University, Guntur, India
}

\begin{abstract}
Microsatellites are easy to genotype and densely distributed throughout eukaryotic genomes, making them the preferred genetic marker for high resolution genetic mapping. The use of DNA marker technology in poultry as a strains identification has progressed rapidly during the last decade. In our case, Simple Sequence Repeats (SSR) analysis for 56 individuals male and female belonging to fast white broiler and Rainbow rooster multicolored dual purpose birds (fast white female( A), fast white male(B), Rainbow rooster female $(C)$ and Rainbow rooster male $(D)$ using four primers. A total of 480 bands in different loci is generated, range of molecular weight start from 97-2708.
\end{abstract}

Keywords: Microsatellites, Germ Plasm, Miniprep, Genetic mapping, Dendrogram

\section{Introduction}

Commercial broiler production and layer farming is highly capital oriented and competitive. Both are serious business ventures and are beyond the reach of the small farmer. Grain and poultry feed become very expensive and native birds with low growth potential, broodiness and poor laying (only 60 eggs in an year ) are no more viable. Dual purpose birds with all attributes of native, faster Growth, less Fat, Tasty Meat and more Eggs suit the small farmer. These birds also thrive on low inputs and meet the gap of nutritional security of densely population countries, they also add to the additional income for the house wife.

Rainbow rooster multicolored dual purpose breed cross, suitable for Back Yard rearing and "Organic Chicken" Production, Breed by Indbro Research \& Breeding farms Pvt. Ltd. at Hyderabad (India) and distributed by vet Frontiers in East and central Africa with distribution centers in Eldoret, Kenya and kampala, Uganda . The Breeder stock are well vaccinated and maintained under strick Bio-security to produce a chick with good livability and excellent performance. The Rainbow Rooster chick is a product of fast growing broilers, high laying brown birds and disease resistant native Germ Plasm. fast growth potential in the first 6 weeks help in less brooding efforts, less fat, tasty and higher meat yield compared to Native Birds.

\section{Materials and Methods}

DNA Isolation

mdigDNA Miniprep kit were using to Obtaining highly pure gDNA from blood of 56 individuals male and female belonging to fast white broiler and Rainbow rooster multicolored dual purpose birds (fast white female( A), fast white male(B), Rainbow rooster female (C)and Rainbow rooster male(D) .

\section{SSR PCR}

Simple Sequence Repeats (SSR) was done by using four primers of ADL0306, MberA4-10,ADL0278 and SULT1B1 (Table 1) The mixtureof the PCR reaction had a final volume of $25 \mu \mathrm{l}$ andcontained $2 \mathrm{ul}$ of genomic DNA, 10x GC buffer -3 ul, dNTP - 1 ul, MgCl2 - 1 ul, SSR primer - 1 ul,Taq poly- 0.5 ul,ddH2O -16.5 ul, The PCR was performed in ,Bio-Rad Thermo cycler ${ }^{\text {ee }}$ using the following cycling parameters: Cycle 1 denaturation $\left(94^{\circ} \mathrm{C}\right) 5$ minutes, annealing $\left(49^{\circ} \mathrm{C}, 53^{\circ} \mathrm{C}, 55^{\circ} \mathrm{C}, 57^{\circ} \mathrm{C}\right) 30$ second and extension $\left(72^{\circ} \mathrm{C}\right) 1$ minutes followed by 36 cycle denaturation $\left(95^{\circ} \mathrm{C}\right)$ 1 minute, and final extension $\left(72^{\circ} \mathrm{C}\right) 10$ minutes. The PCR products were tested with electrophoresis on $1.5 \%$ agarose gels in $0.5 \mathrm{x}$ TBE buffer at 90v for 1 hour. (Promega, USA) stained by ethidium bromide. An external DNA ladder was used to verify the band size and their relative position. The separated gel was pictured by using a Gel Documentation System.

\section{Statistical Analysis}

To analyze SSR results, a software Total lab was used. On the basis of molecular weight, generated dendrogram, so that similarity and dissimilarity among various chicken samples can be calculated easily.

\section{Results}

Table 1: Sequence of primers designed from SSR

\begin{tabular}{|l|c|c|c|c|c|}
\hline & PRIMER & Forward Sequence & Reverse Sequence & Primer Length & Annealing Temperature \\
\hline A & ADL0306 & TCAGTTTGACTTTCCTTCAT & GTTACTGTATCTTGGCTCAT & 20 & 49 \\
\hline B & MberA4-10 & GTCCTTGCCAGAGGCTTC & TGGGTCAGACGGGCTTTG & 18 & 53 \\
\hline C & ADL0278 & CCAGCAGTCTACCTTCCTAT & TGTCATCCAAGAACAGTGTG & 20 & 55 \\
\hline D & SULT1B1 & CACTGTCTGGGTTGGGAATG & GGCTCCGTAACGCAGTCTGT & 20 & 57 \\
\hline
\end{tabular}




\section{International Journal of Science and Research (IJSR) \\ ISSN (Online): 2319-7064}

Index Copernicus Value (2013): 6.14 | Impact Factor (2014): 5.611

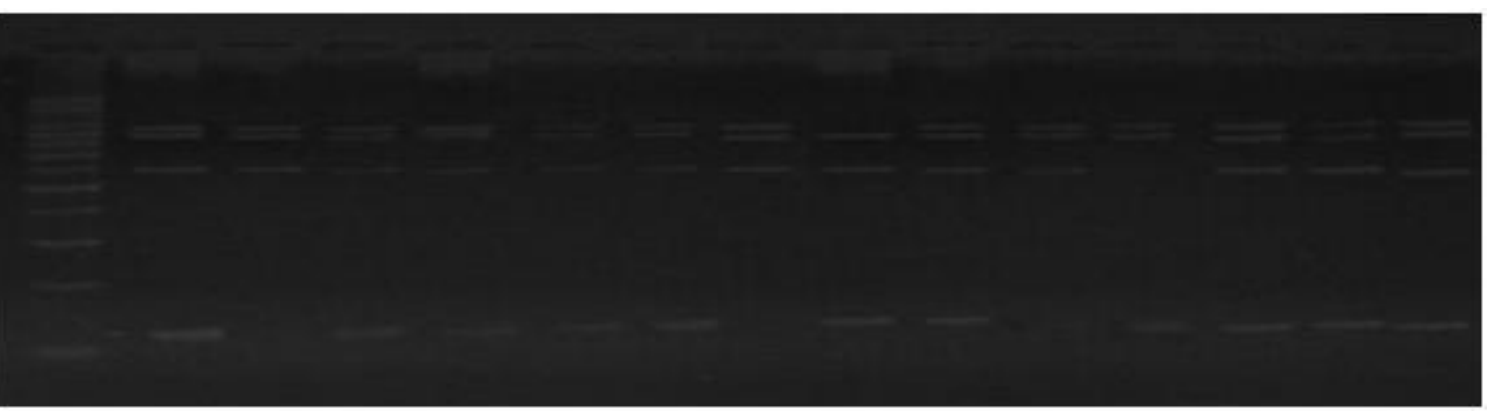

Plate 1: SSR gel profile generated for 14 accessions (AC) using primer (ADL0306)

M BB1 BB2 BB3 BB4 BB5 BB6 BB7 BB8 BB9 BB10 BB11 BB12 BB13 BB14

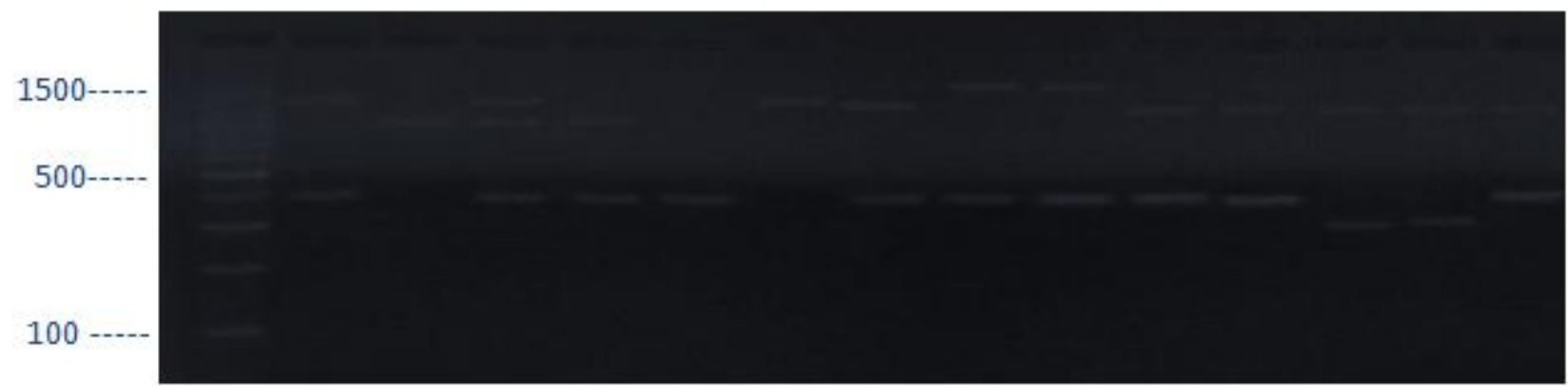

Plate 2: SSR gel profile generated for 14 accessions(BB) using primer (MberA4-10)

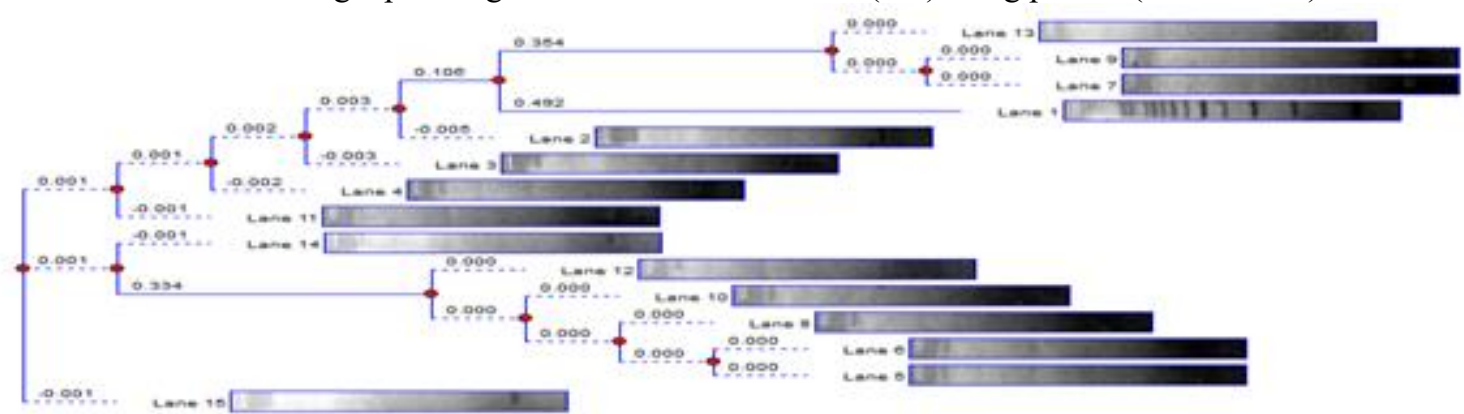

Figure 1: Dendrogram showing diversity of 14(CA) genotypes generated by SSR markers using primer (ADL0278)

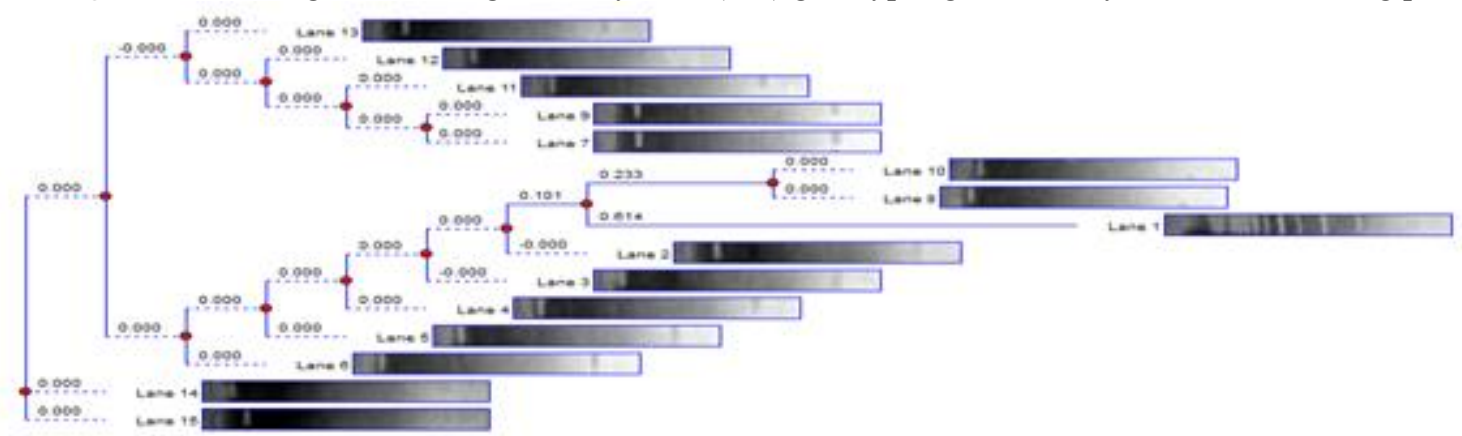

Figure 2: Dendrogram showing diversity of 14(DD) genotypes generated by SSR markers using primer (SULT1B1)

Volume 5 Issue 1, January 2016

www.ijsr.net 


\title{
International Journal of Science and Research (IJSR) \\ ISSN (Online): 2319-7064
}

Index Copernicus Value (2013): 6.14 | Impact Factor (2014): 5.611
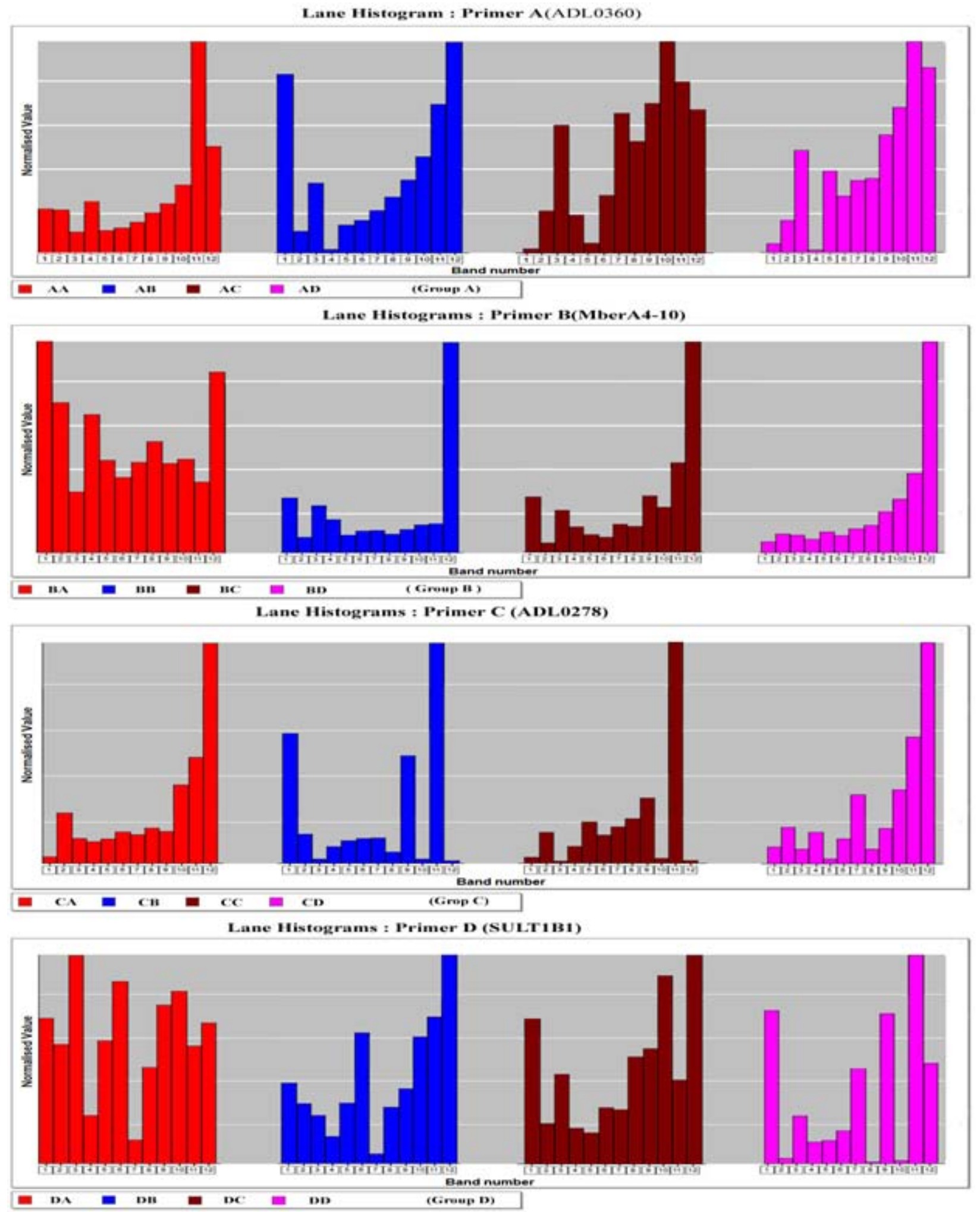

Figure 3: Histogram of (ADL0306) , (MberA4-10), (ADL0278) and (SULT1B1) SSR Primer to show the similarity between four family chicken based on them band pattern

Volume 5 Issue 1, January 2016

\author{
www.ijsr.net
}




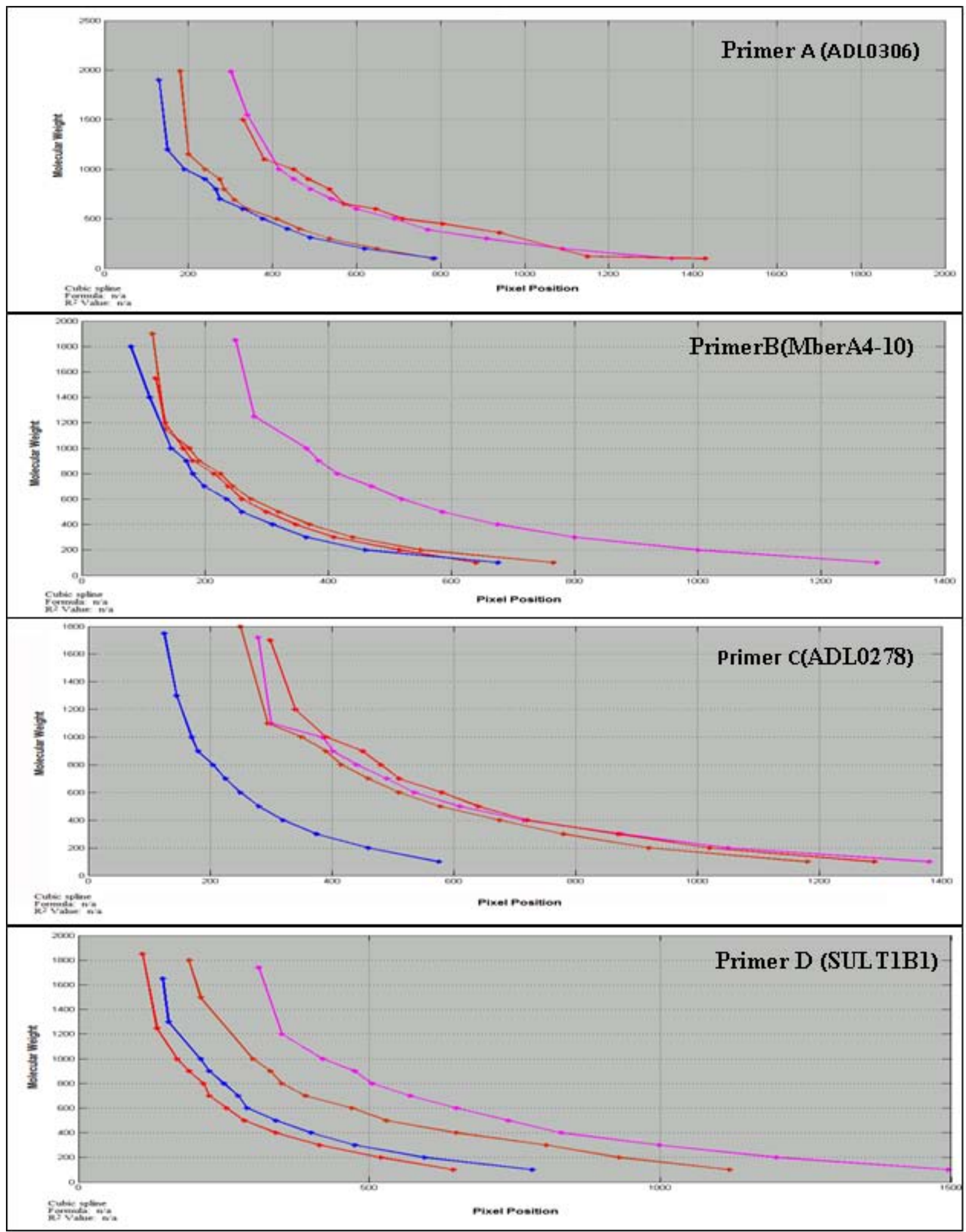

Figure 4: A cubic spline composed of 48 polynomial segments, this shape is used as a range of molecular weight of banding appear in (ADL0306), (MberA4-10), (ADL0278) and (SULT1B1) SSRprimer with 56 chicken samples 


\section{International Journal of Science and Research (IJSR) \\ ISSN (Online): 2319-7064}

Index Copernicus Value (2013): 6.14 | Impact Factor (2014): 5.611

Table 2: details of four SSR Primers with four chicken generations



\section{Conclusion}

Dendrogram generated by Totallab software clearly showing the dissimilarity among chicken sample which cause different weight genotypic. The tables generated on the basis of those differences are an attempt to make sure why they developed with different body size.

\section{Future Scope}

Poultry forms are one of the major sources of providing chicken meat in high populated country like India. Growing big size chicken will be one of the great steps in order to increase food productivity. With these information provided in this research paper will help how to increase and select different chicken species.

\section{References}

[1] Rahimi, G., A. Khanahmadi, A. Nejati-Javaremi and S. Smailkhanian, 2005. Evaluations of genetic variability in a breeder flock of native chicken based on randomly amplified polymorphic DNA markers. Iran. J Biotechnol., 3: 231-234.

[2] Kaya, M. and M.A. Yildiz, 2008. Genetic diversity among Turkish native chickens, Denizli and Gerze, estimated by microsatellite markers. Biochem. Genet, 46: 480-491.

[3] Zhou and Lamount 1999, Wimmers et al. 2000, Wardęcka et al. 2002, Kerje et al. 2003, Jacobsson et al. 2004, Lujiang et al. 2006, Tadano et al. 2007a, b.

[4] Fulton J.E. (2008): Molecular genetics in a modern poultry breeding organization. World's Poult. Sci., 64: 171-176.

[5] Ola A. Galal, Medhat R. and Ragaa E. Abd-El- Karim (2013): Analysis of genetic diversity within and among four rabbit genotypes using biochemical and molecular genetic markers. Afri. J. Biotechnol., 12 (20): 28302839.

[6] Nikkhoo M., Hadi S., Ghodrat R., Mozhdeh N., Farnaz F. and Minoo K. (2011): Measurement of genetic parameters within and between breeder flocks of Arian broiler lines using randomly amplified polymorphic DNA (RAPD) markers. Afri. J. Biotechnol., 10 (36): 6830-6837.

[7] http://www.ncbi.nlm.nih.gov

\section{Volume 5 Issue 1, January 2016}




\section{Author Profile}

Mr. Ahmed Kareem Hussein ALatafi is pursuing PhD-in Animal Genetics and Breeding, in Acharya Nagarjuna University, Guntur, India.

Dr. Kondapalli Kasturi, Assistant Professor, Department of Biotechnology, Acharya Nagarjuna University, Guntur, India 